\title{
Androgen therapy and atherosclerotic cardiovascular disease
}

\author{
K-CY McGrath' \\ LS McRobb ${ }^{1,2}$ \\ AK Heather ${ }^{1,2}$ \\ 'Heart Research Institute, \\ Camperdown, NSW, Australia; \\ ${ }^{2}$ Discipline of Medicine, University \\ of Sydney, Sydney, NSW, Australia
}

\begin{abstract}
Cardiovascular disease (CVD) remains the leading cause of death in Western society today. There is a striking gender difference in CVD with men predisposed to earlier onset and more severe disease. Following the recent reevaluation and ongoing debate regarding the estrogen protection hypothesis, and given that androgen use and abuse is increasing in our society, the alternate view that androgens may promote CVD in men is assuming increasing importance. Whether androgens adversely affect CVD in either men or women remains a contentious issue within both the cardiovascular and endocrinological fraternities. This review draws from basic science, animal and clinical studies to outline our current understanding regarding androgen effects on atherosclerosis, the major CVD, and asks where future directions of atherosclerosis-related androgen research may lie.
\end{abstract}

\section{Introduction}

Epidemiological studies have shown there is a striking gender difference in cardiovascular disease (CVD) with men having higher rates of clinical events than women (Kalin and Zumoff 1999). These findings, together with the increased incidence of CAD in women after menopause (Tracy 1966), have led to the dogma that female hormones protect against the development of CVD (Jeanes et al 2007). The opposite hypothesis, that male hormones may promote CVD in men, has been little investigated. With prospects of androgens being introduced widely for non-classical therapeutic applications, an important clinical question is: do androgens increase the risk or severity of CVD? Such androgen therapy is being targeted towards our aging population, a population that would have pre-existing CVD. The recent proposal that stems from the female hormone replacement therapy (HRT) studies is that HRT appears beneficial in females only when it is initiated before the development of significant atherosclerosis (Rossouw et al 2007). Whether this is also true for androgen-based therapies is unknown. This review explores what is known about androgens and their gender-specific effects on the pathogenesis of atherosclerosis to try and highlight those questions that need to be answered for the safe use of androgen-based HRT in both men and women.

\section{Risk factors of atherosclerosis}

Primary risk factors for atherosclerosis include elevated levels of low-density lipoprotein (LDL), increased levels of homocysteine, hypertension, diabetes mellitus, obesity, smoking, increasing age and also male gender (Ross 1999). In all developed countries, men have an earlier and greater incidence of heart disease than women (Liu et al 2003; Wu and von Eckardstein 2003; Isidori et al 2005). This may be one of the oldest clues to the underlying pathogenic mechanisms of atherosclerosis and suggests that gender-related differences between men and women drives, at least in part, the disparate atherosclerotic plaque formation (Liu et al 2003). There remains no clear
Correspondence: Alison Heather Heart Research Institute, I 4 Pyrmont Bridge Road, Camperdown, NSW 2050, Australia

Tel +6I 282088900

Fax +6I 295503302

Email heathera@hri.org.au 
evidence, to date, that there is a genetic contribution to the male predisposition to atherosclerosis, however the androgenic milieu may underlie plaque formation in men.

\section{Molecular mechanisms of androgen action}

The molecular machinery mediating cellular responses to androgens is complex and involves both genomic and nongenomic effects that are still far from being clearly understood (Figure 1). Genomic effects of androgens are mediated by a specific receptor, the androgen receptor (AR). In response to the binding of androgens to AR, it switches to a transcription factor that regulates target gene expression (Davison and Bell 2006). Non-genomic effects of androgens occur independently of AR. Instead, membrane-bound receptors have been proposed to trigger rapid effects of androgens that lead to 2 nd messenger signaling (Benton et al 2004). This, in turn, triggers a variety of cell responses (Wierman 2007). These nongenomic pathways underlie the rapid vasodilation of coronary arteries by testosterone (Malkin et al 2006; Cooper et al 2007; Seyrek et al 2007).

\section{Regulation and tissue expression of AR}

AR function and transactivation ability is regulated by posttranslational modifications such as phosphorylation (Zhou et al 1995; Gioeli et al 2002), acetylation and sumoylation (Thomas et al 2004). AR expression itself is regulated at both the mRNA and protein levels by androgens (Lee and Chang 2002). Androgens predominantly decrease AR mRNA at

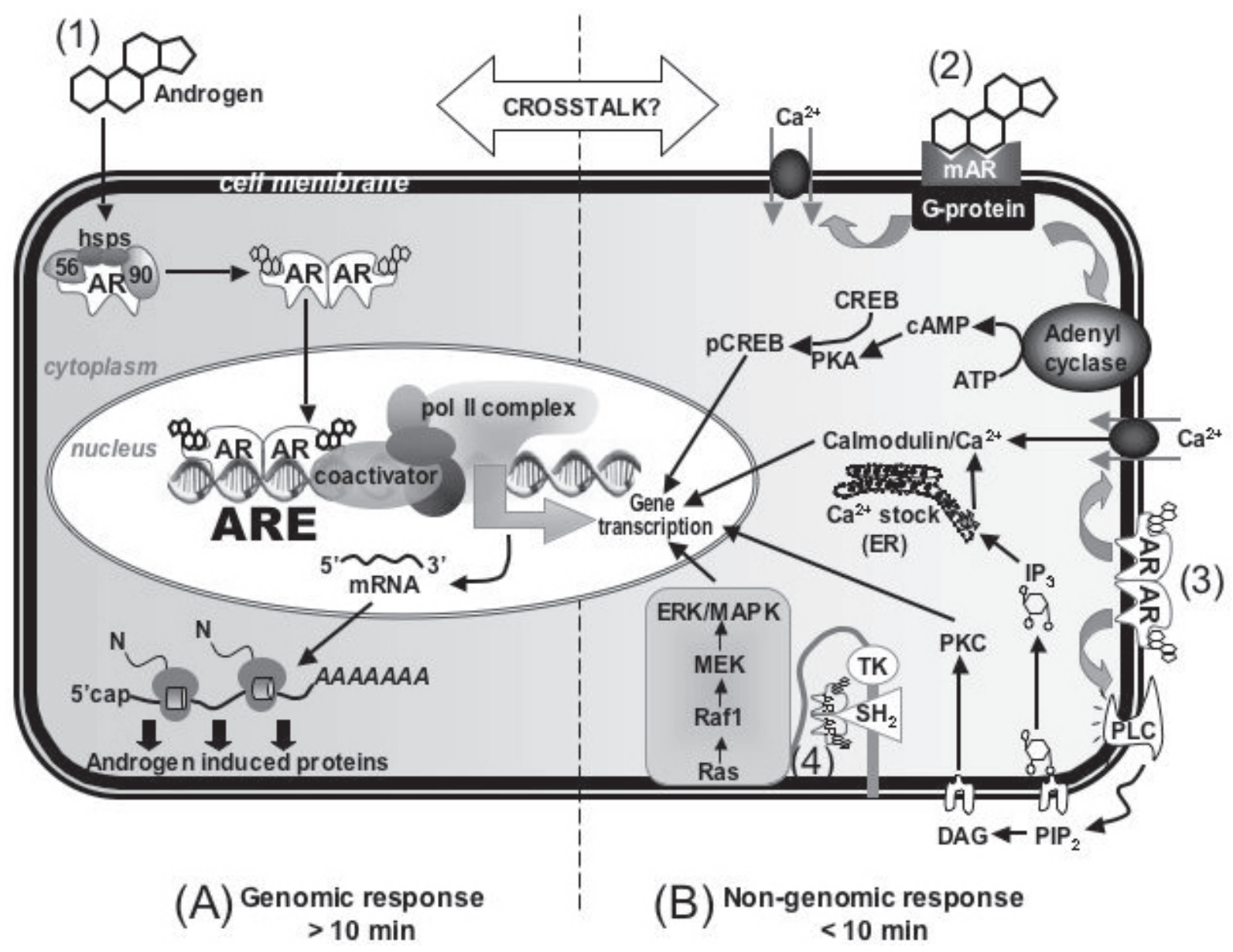

Figure I Molecular mechanisms of androgen action. (I) Androgens mediate gene transcription via binding to the classical cytosolic AR in the genomic pathway; (2) Androgens mediate rapid effects through a novel membrane receptor; (3) Androgens interact with the classical cytosolic AR associated with the plasma membrane; (4) Androgens act through a multi-protein complex associated with the plasma membrane.

Abbreviations: AR: androgen receptor; hsps: heat shock proteins; ARE: androgen response element; mRNA: messenger RNA; mAR:putative membrane AR; cAMP: cyclic adenosine monophosphate; PKA: protein kinase A;ATP: adenosine triphosphate; CREB:cAMP response element binding protein; pCREB: phosphorylated CREB; PLC:phospholipase C; PIP2: phosphatidyl inositol bisphosphate; DAG: diacylglycerol; IP3: inositol 3-phosphate; PKC: protein kinase C; ER: endoplasmic reticulum; SH2: Src homology domain;TK: tyrosine kinases; MEK: mitogen activated protein kinase-extracellular signal regulated kinase; ERK: extracellular signal regulated kinase; MAPK: mitogen-activated protein kinase. 
the transcriptional level (Trapman et al 1990; Krongrad et al 1991) however, they simultaneously increase AR stability and translational efficiency thereby even in the presence of decreased AR mRNA levels, androgens increase AR protein levels in most cell types (Yeap et al 1999).

AR has been detected in the majority of tissues throughout the body (Quigley et al 1995). AR is evident in vascular cells and gender-specific expression of AR has been shown in monocytederived macrophages ( $\mathrm{Ng}$ et al 2003), endothelial cells (Death et al 2004) and vascular tissue (Death et al 2004), where cells or tissue from male donors had significantly higher AR protein levels. The gender dichotomy in AR expression may underlie gender-specific effects of androgens on atherosclerosis.

\section{Metabolic activation of testosterone}

Testosterone and other androgens can mediate effects via metabolic activation (Figure 2). This involves the conversion of testosterone at peripheral nongonadal tissues to active metabolites, estradiol or DHT. Conversion of testosterone to estradiol involves a P450-dependent aromatase enzyme (CYP19) and acts to diversify androgen action, since estradiol binds to the estrogen receptor (ER), and not $A R$, thereby regulating the expression of a completely different set of genes. The conversion of testosterone to DHT is catalyzed by $5 \alpha$-reductases. DHT has greater binding affinity for AR than testosterone and a slower dissociation rate, therefore has a higher molar potency (Grino et al 1990). Hence, the conversion of testosterone to DHT effectively amplifies AR action.

\section{Androgens and vascular cell effects}

Androgens have been shown to promote-, and suppress-, pro-atherogenic, pro-inflammatory effects on all cell types involved in atherogenesis. Given current evidence it would appear that androgen effects are dependent on cell type, dose, type of androgen, and time of exposure. For example, T suppresses vascular cell adhesion molecule-1 (VCAM-1) expression in human endothelial cells, via an aromatase/ estrogen receptor-dependent mechanism (Hatakeyama et al 2002; Mukherjee et al 2002); however, DHT, a non-aromatisable androgen, induces VCAM-1 expression in human endothelial cells (Death et al 2004). Similarly, T has been shown to enhance reverse cholesterol transport (Langer et al 2002) whilst DHT promotes cholesteryl ester accumulation in monocyte derived macrophages ( $\mathrm{Ng}$ et al 2003). In addition, $\mathrm{T}$ has been shown to inhibit nitric oxide release from monocytes via inhibition of inducible nitric oxide synthase (Friedl et al 2000). This decrease in NO potentially increases thrombosis risk via increased platelet aggregation.
Additionally, $\mathrm{T}$ has adverse effects stimulating the proliferation of rat vascular smooth muscle cells (Fujimoto et al 1994), inducing proteoglycan synthesis and the elongation of glycosaminoglycans (GAG) chains on these proteoglycans (Hashimura et al 2005) and $\mathrm{T}$ increases apoptotic damage of vascular smooth muscle cells (Ling et al 2004). Importantly, some of the effects on both endothelial cells and MDMs were gender-specific, occurring in cells derived from males but not females, and associated with increased AR expression in male-derived cells ( $\mathrm{Ng}$ et al 2003; Death et al 2004). This suggests that steps in atherogenesis could be markedly different between genders, mediated by androgen exposure and AR expression levels.

Therefore, both T and DHT can have effects that could lead to the development of atherosclerosis, associated with male-dependent AR expression. However, T can have equally anti-atherogenic effects, associated with aromatisation. Obviously, more work is required for us to understand how androgens act at the cellular level. One of the major questions that has recently emerged is whether aromatisation is an important protective mechanism? There is now a real need to study and understand the metabolic activation pathways of $\mathrm{T}$, in those cell types associated with atherosclerosis, and to determine if manipulating those pathways can switch between the atheroprotective versus atherogenic effects of $\mathrm{T}$ ?

\section{Androgens and atherosclerosis: evidence from animal model studies}

As with the cellular studies, androgen treatment has been shown to both promote and retard lesion formation in animal studies of atherosclerosis (Table 1). The effects of T appear to be gender-, steroid/dose/administration-, and/or species- specific. For the most part, $\mathrm{T}$ treatment of male animals has led to a decrease in atherosclerotic lesion size or the atherosclerosis-related end point studied (e.g. aortic cholesterol content) (Bruck et al 1997; Elhage et al 1997; Alexandersen et al 1999; Nathan et al 2001). Similarly, DHEA treatment of male animals has led to a decrease in atherosclerosis (Gordon et al 1988; Arad et al 1989; Eich et al 1993). Both T and DHEA are readily aromatisable to estradiol, and aromatase inhibition has been shown to block the atheroprotective effects of $T$ (Nathan et al 2001). In keeping with the importance of aromatase to mediate the atheroprotective effects of $\mathrm{T}$, a study showed that a 3-month treatment with an anabolic androgenic steroid, stanozolol, had no effect on atherosclerosis or blood lipids in cholesterol-fed rabbits (Fogelberg et al 1990). Stanozolol is a $5 \alpha$-reduced substrate so it cannot be converted to estrogen 


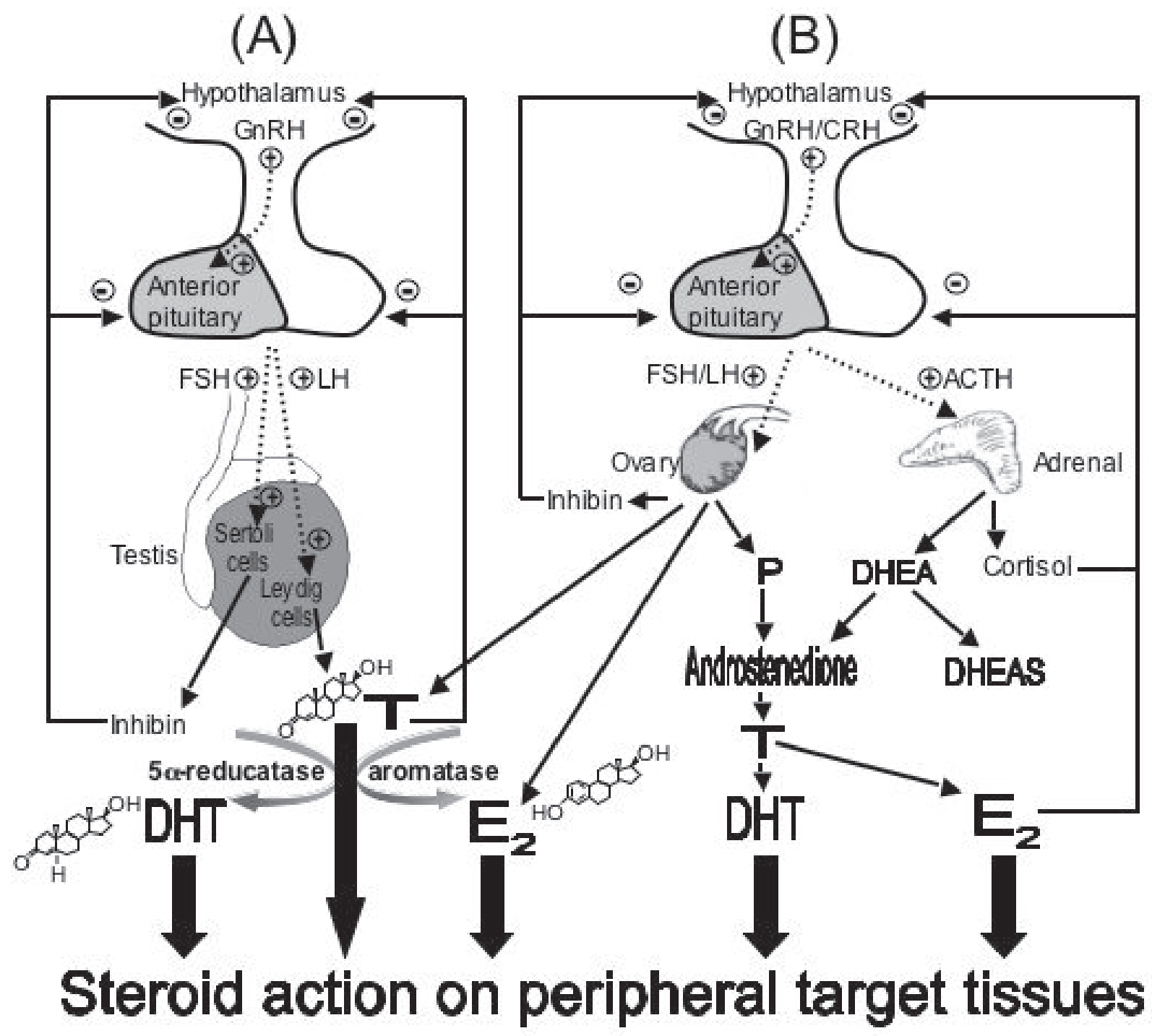

Figure 2 Schematic representation of the major sources of androgens in men and women. (MEN) The hypothalamic-pituitary-gonadal axis in men. The dotted lines represent the pulsatile release of gonadotropin-releasing hormone $(\mathrm{GnRH})$, follicle-stimulating hormone (FSH) and luteinising hormone $(\mathrm{LH})$. $\mathrm{LH}$ serves to stimulate the testis to produce testosterone ( $\mathrm{T}$ ) or FSH stimulates production of inhibin. In turn, these exert a negative feedback on both the pituitary and hypothalamus regulating LH and FSH secretion. T can be reduced to the more active dihydrotestosterone (DHT) or aromatised to estradiol (E2) in target tissues. (WOMEN) The hypothalamic-pituitary-ovarian and hypothalamic-pituitary-adrenal axis represents the major sources for androgen synthesis in women. In addition to inhibin and cortisol, high levels of E2, progesterone (P) and adrenal androgens exert a negative feedback to regulate the secretions of GnRH, corticotropin-releasing hormone (CRH), FSH, LH and adrenocorticotropic hormone $(\mathrm{ACTH})$.

by aromatase and therefore, only has androgenic effects. Interestingly, 2/10 stanozolol-treated normal diet fed rabbits developed atherosclerosis versus $0 / 72$ control rabbits, thereby suggesting that stanozolol may increase the propensity for atherosclerotic lesion development. This was not followed up by these investigators.

In contrast to the studies that showed $\mathrm{T}$ was atheroprotective, two studies (out of 12) demonstrated increased atherosclerotic plaque formation after exogenous $\mathrm{T}$ treatment (Toda et al 1984; von Dehn et al 2001). However, both of these studies used an experimental approach that differed from usual practice. The first studied chicks, rather than rodents, and they only observed increased atherosclerotic lesion when $\mathrm{T}$ was administered at $150 \mathrm{mg}$ for 7 weeks (compared to 50 $\mathrm{mg} /$ day/rabbit for 3 months, Bruck et al 1997). No studies have subsequently been performed in chicks to confirm the original findings. The second study demonstrating adverse effects of $\mathrm{T}$ used chemical, rather than surgical, castration of apoE-deficient mice. In this model, T treatment $(35 \mathrm{mg}$ dosage) was observed to increase atherosclerotic lesion area by a significant, but small, extent. This study did not examine the aromatase pathway so in this animal model it is not clear 


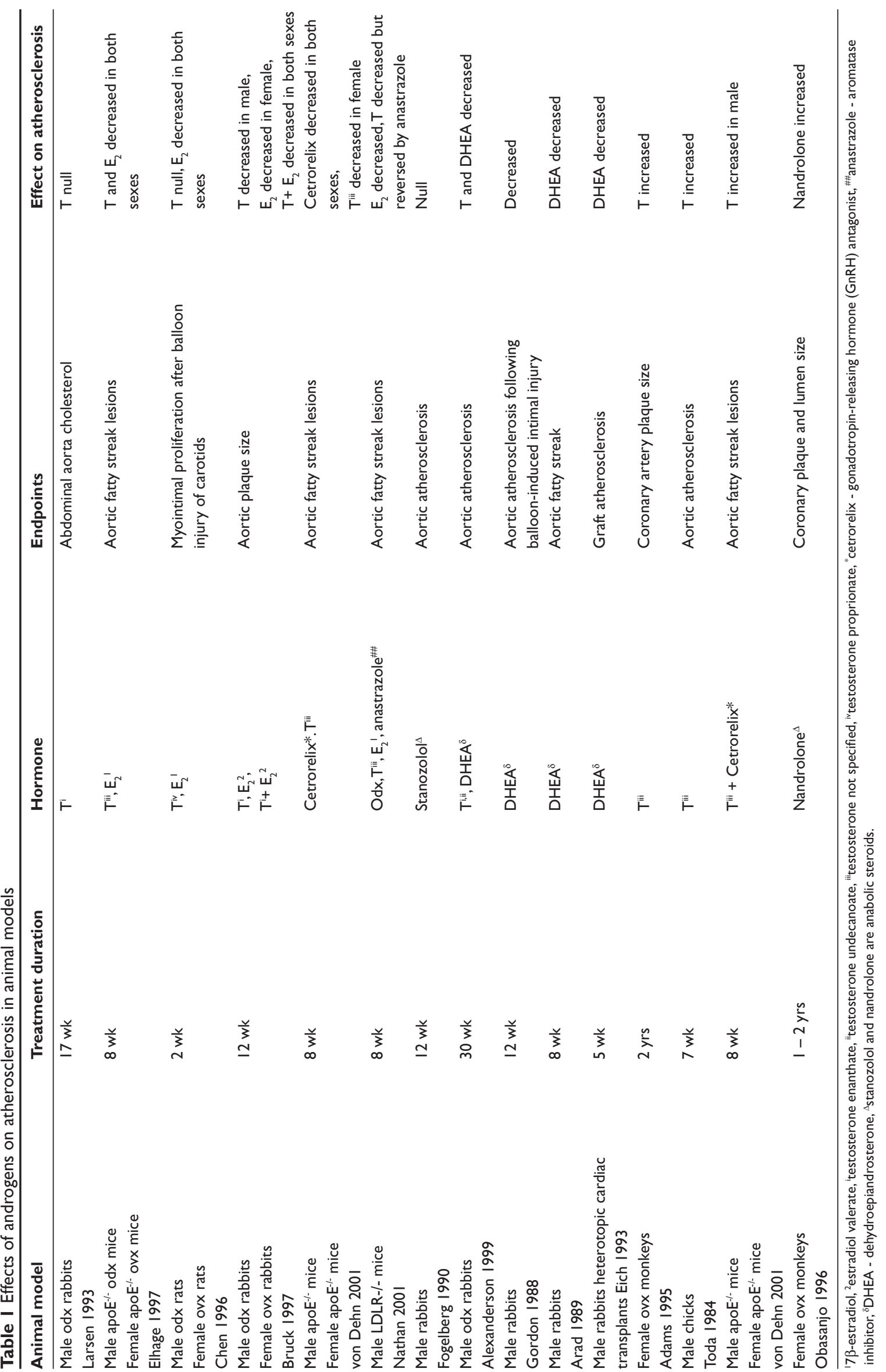


if aromatase would be expressed, which could help explain the disparate result.

As with the male animal model data, testosterone effects on atherosclerotic plaque formation in female animal models is also contentious. The data that exists is very limited with only 5 studies in total. Three of these studies were performed in rodents and testosterone was found to decrease lesion size in 2/3 of them (Elhage et al 1997; von Dehn et al 2001). The third rodent study showed no effect of testosterone treatment on atherosclerotic plaque development (Chen et al 1996). The other two female animal studies were performed with primates and showed that testosterone or the anabolic androgen, nandrolone, induced atherosclerosis over a 2-year treatment period (Adams et al 1995; Obasanjo et al 1996). These primate studies, whilst only have a small number of animals in the experimental groups, remains the strongest evidence that exogenous androgen treatment may be atherogenic in females.

Importantly, all of the animal studies have targeted the effects of androgens on atherosclerotic plaque development without examining an effect of $\mathrm{T}$ on existing plaque. As has now been highlighted by the recent estrogen therapy trials, the timing of hormone therapies can have different outcomes on CVD. Although contentious, and remains to be proven, estrogen-based therapies given after plaque has developed leads to adverse effects (increased myocardial infarction, stroke) in the short-term. Whether androgen-based therapies have similar outcomes dependent on timing and age of patient has not been investigated.

Figure 3 summarizes the primary effect of androgen and estrogen treatment on atherosclerotic lesion development, as measured in animal studies. Note that many more studies have targeted estradiol effects and the number of androgen studies are relatively small in comparison, especially those that focus on $\mathrm{T}$ effects in females. Therefore, it remains unclear whether $\mathrm{T}$ is anti- or pro-atherogenic in female animal models, whilst in males $\mathrm{T}$ is atheroprotective, most probably via aromatisation to estradiol. Direct T or stanozolol effects appear to be atherogenic, although the limited number of studies do not allow for any firm conclusions to be made. Therefore, androgens, atherosclerosis, and gender-specific effects remains an important area for future research development.

\section{Androgens and atherosclerosis: evidence from clinical studies}

To date, the major clue that androgens may drive CAD in men remains the gender dichotomy in the earlier incidence of atherosclerosis. However, epidemiologic studies report no association between high physiologic androgen levels and atherosclerosis (English et al 2000; Hak et al 2002; Muller et al 2004). Instead, the inverse has been reported namely that hypoandrogenemia associates with CAD (Malkin et al 2003), or an atherogenic lipid profile (Tchernof et al 1997; Zmuda et al 1997), metabolic syndrome (Kupelian et al 2006), type 2 diabetes (Haffner et al 1996; Stellato et al 2000), systolic and diastolic hypertension (Svartberg et al 2004), visceral obesity (Khaw and Barrett-Connor 1992), increased fibrinogen (Bonithon-Kopp et al 1988), arterial stiffness (Hougaku et al 2006) and all-cause or cardiovascular deaths (Barrett-Connor and Khaw 1988). Hypoandrogenemia is common and it has been reported that $10 \%$ of men between 40 and 60 years of age and $25 \%$ between 60 and 80 years of age have low levels of free $\mathrm{T}$ (Vermeulen and Kaufman 2002) therefore hypo- rather than hyper- androgenemia may be the gender-specific factor driving atherosclerosis. However, not all studies have found an association between hypoandrogenemia and increased CVD (Contoreggi et al 1990) therefore it is difficult to draw any firm conclusions. It is of interest that castration of male rodents has been shown to increase atherosclerosis in animal models of atherosclerosis (Nathan et al 2001).

Given that low $\mathrm{T}$ levels appear harmful for CVD and its important risk factors, $\mathrm{T}$ supplementation would be expected to be beneficial. Meta-analysis review of cardiovascular safety of $\mathrm{T}$ replacement therapy has reported that $\mathrm{T}$ supplementation was relatively safe in terms of cardiovascular health (Haddad et al 2007). However, this meta-analysis needs to be interpreted with caution as none of the randomized controlled trials that were included in the analysis were designed to assess cardiovascular safety and therefore adverse outcomes may have been censored and/or not reported, therefore, weakening the meta-analysis conclusions. However, other studies have shown that T replacement therapy has demonstrable beneficial effects on CVD risk factors, including waist measurements (Marin et al 1992), visceral abdominal fat mass (Marin et al 1992), as well as positive effects on numerous metabolic parameters including insulin sensitivity, glucose control, and hyperlipidemia (English et al 2000; Malkin et al 2006). Direct effects on the arterial tree have also been described with consistent improvement in both anginal symptoms and ischemia on electrocardiograms in men treated with injectable $\mathrm{T}$ preparations (Rosano et al 1990; Webb et al 1999; English et al 2000; Pugh et al 2003).

However, while the observations above would suggest $\mathrm{T}$ supplementation improves CVD risk factors, meta-analysis 


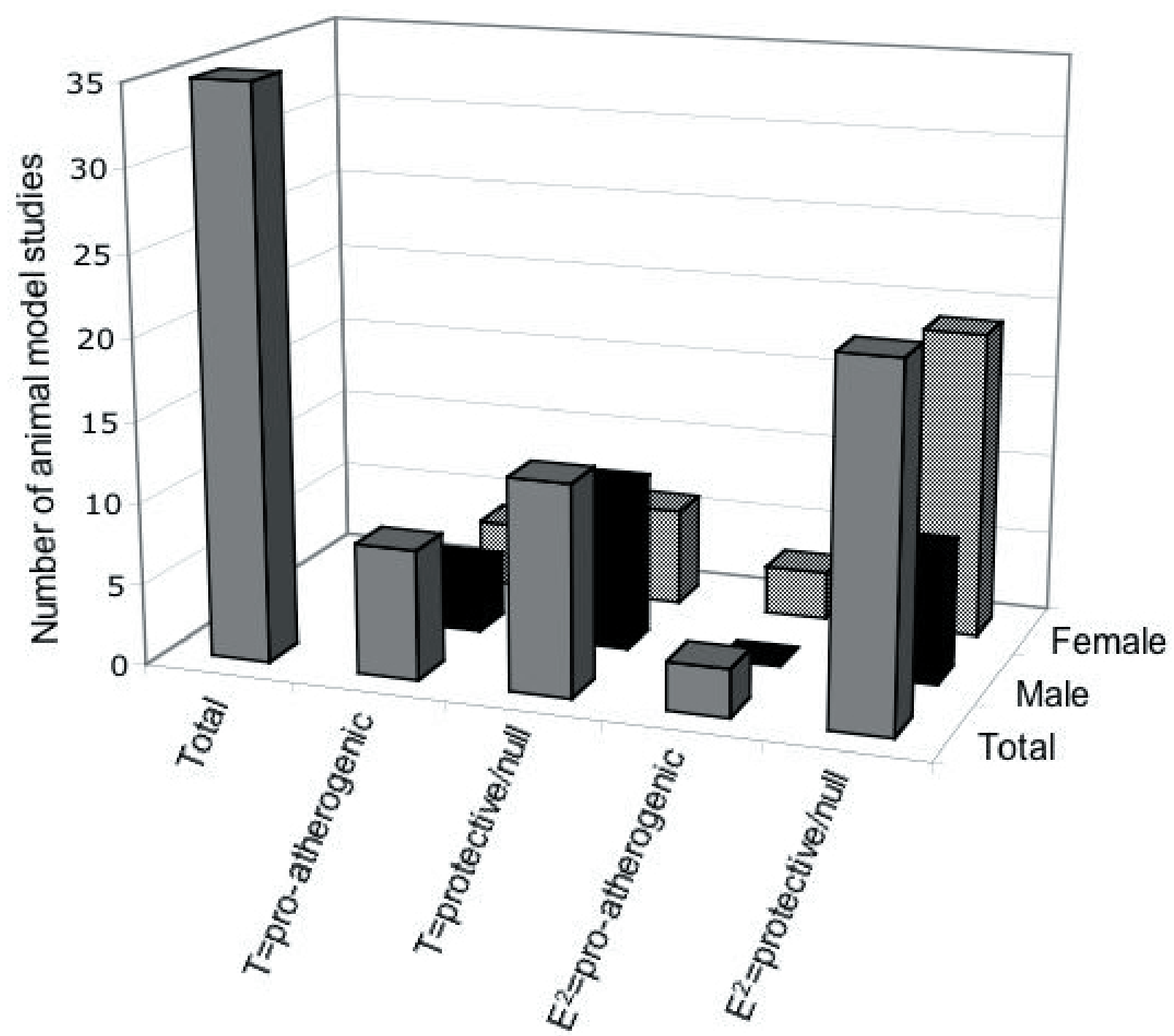

Figure 3 Animal model studies examining the effects of androgens on atherosclerosis. Total number of animal model studies are represented by the solid grey bar. Of the total number of studies, male studies are represented by the black solid bar. Of the total number of studies, female studies are represented by the hatched bar. $T=$ proatherogenic - represents the number of animal model studies showing pro-atherogenic effects of $\mathrm{T}$ treatment or castration; $\mathrm{T}=$ protective/null - represents the number of animal model studies showing protective or null effects of $T$ treatment or castration; E2=pro-atherogenic - represents the number of animal model studies showing pro-atherogenic effects of $\mathrm{T}$ treatment or castration; $\mathrm{E} 2=$ protective/null - represents the number of animal studies showing protective or neutral effects of $\mathrm{T}$ treatment or castration.

by Whitsel et al (2001) found a dose-dependent decrease in HDL-C and total cholesterol levels with T use in hypogondal men. Similarly, small intervention trials have demonstrated that exogenous $\mathrm{T}$ supplementation in young men lowers HDL (Meriggiola et al 1995; Wu et al 1996) but in older men T did not affect HDL (Snyder et al 2001; Page et al 2005). The disparite findings may indicate that the effect of $\mathrm{T}$ replacement on HDL may be age-dependent. Any effect of T on lowering HDL-C needs to be considered as low HDL levels are a strong risk factor for CVD (Gordon et al 1997).

Other cardiovascular diseases that often coexist with CVD, including hypertension and ischemic stroke, also show a similar gender bias, with males at higher risk. Androgens have been reported to adversely affect both conditions, with reports of prohypertensive effects (Jenkins et al 1994; Reckelhoff 2005) and to worsen the acute phase of stroke (Hawk et al 1998). Therefore, when considering T replacement therapy in aging men, the effect on atherosclerosis cannot be considered without simultaneously investigating hypertension and stroke (Figure 4).

Anabolic androgenic steroid (AAS) use has been anecdotally associated with various forms of cardiovascular disease. Self-administration of AAS has been linked with sudden cardiac death, androgen-induced vasospasm, platelet 


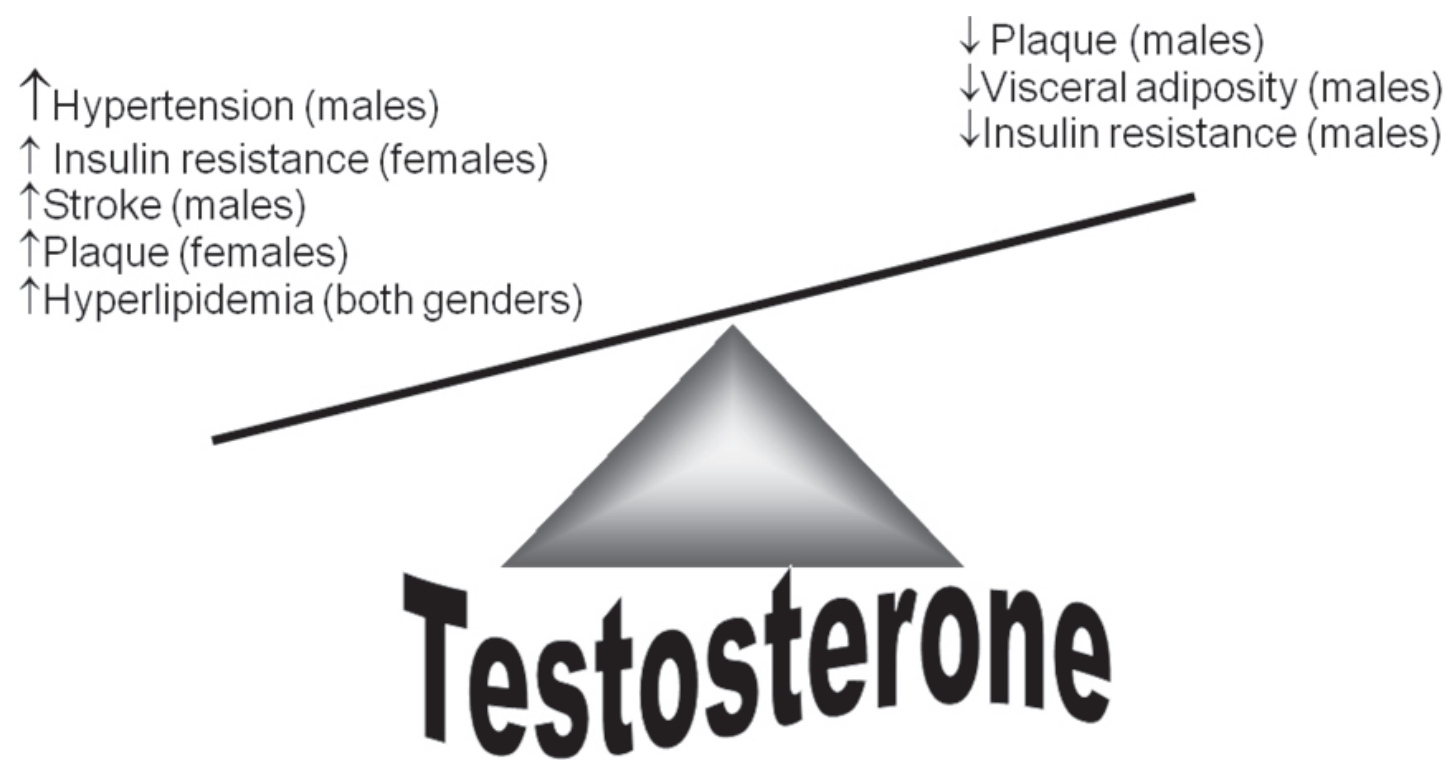

Figure 4 Summary of the effects of exogenous $T$ treatment on cardiovascular endpoints.

aggregation, activation of the coagulation cascade, and abnormal left ventricular function and hypertrophy (Maron et al 1996). It has also been reported that self-administration of several AAS simultaneously for 8 or 14 weeks produces profound unfavorable effects on lipoproteins and lipids, leading to an increased atherogenic profile (Hartgens et al 2004). However, any link between the adverse lipid profile induced by AAS use and increased atherosclerosis remains to be established.

In women, it is much clearer that androgen excess is linked to the burden of CVD risk factors. The most well studied of such risk factors is insulin resistance. It has been hypothesized that insulin resistance is a consequence of androgen effects. Excessive androgenic steroid exposure of female rats (Holmang et al 1990), normal females (Polderman et al 1994), transsexual females (Bjorntorp 1993), and patients with aplastic anemia (Woodard et al 1981) can lead to insulin resistance and may at least be partly reversed by estrogen administration (Andersson et al 1997). In keeping with this hypothesis, it was recently demonstrated that postmenopausal women with well-controlled type 2 diabetes that are insulin resistant show evidence of biochemical and clinical androgen excess, compared to non-diabetic, postmenopausal women with no known risk factors for diabetes other than obesity (Korytkowski et al 2005). Further evidence of a link between high androgen levels and CVD or CVD risk factors is observed in women with polycystic ovary syndrome (PCOS). Women with PCOS have a sustained exposure to high physiologic androgen levels. This condition is associated with endothelial dysfunction, obesity and metabolic abnormalities such as insulin resistance and dyslipidaemia, all of which may predispose PCOS women to premature atherosclerosis (Paradisi et al 2001; Krentz et al 2007).

However, despite the association between excess androgen in women and insulin resistance, CVD risk factors and angiographical evidence of atherosclerosis, there remains no evidence of increase cardiovascular mortality in these women. Additionally, in female-to-male transsexuals, testosterone therapy has not been linked to excess cardiovascular mortality or morbidity (van Kesteren et al 1997). Therefore, the question of the cardiovascular safety of androgen therapy in women remains unanswered. Based on existing observations, androgen use may increase insulin resistance in women with a consequent sequalae of cardiovascular effects however apart from the observations in women with PCOS and type 2 diabetes, and animal data suggesting androgens promote atherosclerosis in females, there is no solid data to support the claim (Figure 4). More work is necessary to establish a real link between androgens, insulin resistance and atherosclerosis in women.

\section{Summary}

From our current understanding of the effects of androgens on atherosclerosis, it has become apparent that the view androgens are harmful is too simplistic. This is made most evident by the erratic nature of the findings reported in cellular, animal and clinical studies. Clearly, much more work is needed in both the basic science and clinical arenas to 
fully elucidate the effects of androgens on the development of atherosclerosis. For men, exogenous T treatment appears largely beneficial, at least in part via aromatization of $\mathrm{T}$ to estradiol, especially if physiological $\mathrm{T}$ levels are deficient. However, self-administered AAS usage remains a major CVD safety concern, especially given reported adverse lipid profile effects. As clinicians consider the use of $\mathrm{T}$ in management of symptoms associated with the aging male, there remains inconsistent and poorly reported data on cardiovascular risk of long-term $\mathrm{T}$ use. For $\mathrm{T}$ treatment in aging women, the current data would suggest androgen excess has adverse effects on CVD risk factors, especially in women with diabetes. In summary, there remains limited knowledge about exogenous androgen treatments in both men and women. Despite this, androgen use and abuse is increasing in our society, either for therapeutic or recreational reasons. Whether androgens adversely affect CVD in either men or women remains a contentious issue that is in desperate need of more research.

\section{References}

Adams MR, Williams JK, Kaplan JR. 1995. Effects of androgens on coronary artery atherosclerosis and atherosclerosis-related impairment of vascular responsiveness. Arterioscler Thromb Vasc Biol, 15:562-70.

Alexandersen P, Haarbo J, Byrjalsen I, et al. 1999. Natural androgens inhibit male atherosclerosis: a study in castrated, cholesterol-fed rabbits. Circ Res, 84:813-19.

Andersson B, Mattsson LA, Hahn L, et al. 1997. Estrogen replacement therapy decreases hyperandrogenicity and improves glucose homeostasis and plasma lipids in postmenopausal women with noninsulin-dependent diabetes mellitus. J Clin Endocrinol Metab, 82:638-43.

Arad Y, Badimon JJ, Badimon L, et al. 1989. Dehydroepiandrosterone feeding prevents aortic fatty streak formation and cholesterol accumulation in cholesterol-fed rabbits. Arteriosclerosis, 9:159-65.

Barrett-Connor E, Khaw KT. 1988. Endogenous sex hormones and cardiovascular disease in men. A prospective population-based study. Circulation, 78:539-45.

Benton WPM, Guo Z, Krucken J, Wunderlich F. 2004. Rapid effects of androgens in macrophages. Steroids, 69:585-90.

Bjorntorp P. 1993. Hyperandrogenicity in women-a prediabetic condition? J Intern Med, 234:579-83.

Bonithon-Kopp C, Scarabin PY, Bara L, et al. 1988. Relationship between sex hormones and haemostatic factors in healthy middle-aged men. Atherosclerosis, 71:71-6.

Bruck B, Brehme U, Gugel N, et al. 1997. Gender-specific differences in the effects of testosterone and estrogen on the development of atherosclerosis in rabbits. Arterioscler Thromb Vasc Biol, 17:2192-9.

Chen SJ, Li HB, Durand J, et al. 1996. Estrogen reduces myointimal proliferation after balloon injury of rat carotid artery. Circulation, 93:577-84

Contoreggi CS, Blackman MR, Andres R, et al. 1990. Plasma levels of estradiol, testosterone, and DHEAS do not predict risk of coronary artery disease in men. $J$ Androl, 11:460-70.

Cooper BC, Gokina NI, Osol G. 2007. Testosterone replacement increases vasodilatory reserve in androgen-deficient female rats. Fertility and Sterility, 87:422-5.

Davison SL, Bell R. 2006. Androgen physiology. Seminars in Reproductive Medicine, 24:71-7.
Death AK, McGrath KCY, Sader MA, et al. 2004. Dihydrotestosterone promotes vascular cell adhesion molecule-1 expression in male human endothelial cells via a nuclear factor-(B-dependent pathway. Endocrinology, 145:1889-97.

Eich DM, Nestler JE, Johnson DE, et al. 1993. Inhibition of accelerated coronary atherosclerosis with dehydroepiandrosterone in the heterotopic rabbit model of cardiac transplantation. Circulation, 87:261-5.

Elhage R, Arnal JF, Pieraggi MT, et al. 1997. 17(-estradiol prevents fatty streak formation in apolipoprotein E-deficient mice. Arterioscler Thromb Vasc Biol, 17:2679-84.

English KM, Mandour O, Steeds RP, et al. 2000. Men with coronary artery disease have lower levels of androgens than men with normal coronary angiograms. Eur Heart J, 21:890-4.

English KM, Steeds RP, Jones TH, et al. 2000. Low-dose transdermal testosterone therapy improves angina threshold in men with chronic stable angina: a randomized, double-blind, placebo-controlled study. Circulation, 102:1906-11.

Fogelberg M BI, Dicsfalusy U, Henriksson P. 1990. Stanozolol and experimental atherosclerosis: atherosclerosis development and blood lipids during anabolic steroid therapy of New Zealand white rabbits. Scand J Clin Lan Invest, 50:693-700.

Friedl R, Brunner M, Moeslinger T, et al. 2000. Testosterone inhibits expression of inducible nitric oxide synthase in murine macrophages. Life Sci, 68:417-29.

Fujimoto R, Morimoto I, Morita E, et al. 1994. Androgen receptors, 5(reductase activity and androgen-dependent proliferation of vascular smooth muscle cells. J Steroid Biochem Mol Biol, 50:169-74.

Gioeli D, Ficarro SB, Kwiek JJ, et al. 2002. Androgen receptor phosphorylation. Regulation and identification of the phosphorylation sites. Journal of Biological Chemistry, 277:29304-14.

Gordon GB, Bush DE, Weisman HF. 1988. Reduction of atherosclerosis by administration of dehydroepiandrosterone: a study in the hypercholesterolemic New Zealand white rabbit with aortic intimal injury. J Clin Invest, 82:58-64.

Gordon T, Castelli WP, Hjortland MC, et al. 1997. High density lipoprotein as a protective factor against coronary artery disease: the Framingham Study. Am J Med, 62:707-14.

Grino PB, Griffin JE, Wilson JD. 1990. Testosterone at high concentrations interacts with the human androgen receptor similarly to dihydrotestosterone. Endocrinology, 126:1165-72.

Haddad RM, Kennedy CC, Caples SM, et al. 2007. Testosterone and cardiovascular risk in men: a systematic review and meta-analysis of randomized placebo-controlled studies. Mayo Clinic Proc, 82:29-39.

Haffner SM, Shaten J, Stern MP, et al. 1996. Low levels of sex hormone binding globulin and testosterone predict the development of non insulin dependent diabetes mellitus in men. American Journal of Epidemiology, 143:889-97.

Hak AE, Witteman JC, de Jong FH, et al. 2002. Low levels of endogenous androgens increase the risk of atherosclerosis in elderly men: the Rotterdam study. J Clin Endocrinol Metab, 87:3632-9.

Hartgens F, Rietjens G, Keizer HA, et al. 2004. Effects of androgenicanabolic steroids on apolipoproteins and lipoprotein (a).. Br J Sports Med, 38:253-9.

Hashimura K, Sudhir K, Nigro J, et al. 2005. Androgens stimulate human vascular smooth muscle cell proteoglycan biosynthesis and increases lipoprotein binding. Endocrinology, 146:2085-90.

Hatakeyama H, Nishizawa M, Nakagawa A, et al. 2002. Testosterone inhibits tumor necrosis factor-alpha-induced vascular cell adhesion molecule-1 expression in human aortic endothelial cells. FEBS Letters, 530:129-32.

Hawk T, Zhang YQ, Rajakumar G, et al. 1998. Testosterone increases and estradiol decreases middle cerebral artery occlusion lesion size in male rats. Brain Res, 796:296-8.

Holmang A, Svedberg J, Jennische E, et al. 1990. Effects of testosterone on muscle insulin sensitivity and morphology in female rats. Am J Physiol, 259:E555-60. 
Hougaku H, Fleg JL, Najjar SS, et al. 2006. Relationship between androgenic hormones and arterial stiffness, based on longitudinal hormone measurements. Am J Physiol Endocrinol Metab, 290:E234-42.

Isidori AM, Giannetta E, Pozza C, et al. 2005. Androgens, cardiovascular disease and osteoporosis. Journal of Endocrinological Investigation, 28:73-9.

Jeanes H, Newby D, Gray GA. 2007. Cardiovascular risk in women: the impact of hormone replacement therapy and prospects for new therapeutic approaches. Expert Opinion on Pharmacotherapy, 8:279-88.

Jenkins C, Salisbury R, Ely D. 1994. Castration lowers and testosterone restores blood pressure in several rat strains on high sodium diet. Clin Exp Hypertens, 16:611-25.

Kalin MF, Zumoff B. 1999. Sex hormones and coronary disease: a review of the clinical studies. Steroids, 55:330-52.

Khaw KT, Barrett-Connor E. 1992. Lower endogenous androgens predict central adiposity in men. Ann Epidemiol, 2:675-82.

Korytkowski MT, Krug EI, Daly MA, et al. 2005. Does androgen excess contribute to the cardiovascular risk profile in postmenopausal women with type 2 diabetes?. Metabolism Clinical and Experimental, 54:1626-31.

Krentz AJ, von Muhlen D, Barrett-Connor E. 2007. Searching for polycystic ovary syndrome in postmenopausal women: evidence of a doseeffect association with prevalent cardiovascular disease. Menopause, 14:284-92.

Krongrad A, Wilson CM, Wilson JD, et al. 1991. Androgens increase androgen receptor protein while decreasing receptor mRNA in $\mathrm{LNCaP}$ cells. Molecular and Cellular Endocrinology, 76:79-88.

Kupelian V, Page ST, Araujo AB, et al. 2006. Low sex hormone-binding globulin, total testosterone, and symptomatic androgen deficiency are associated with development of the metabolic syndrome in nonobese men. J Clin Endocrinol and Metab, 91:843-50.

Langer C, Gansz B, Goepfert C, et al. 2002. Testosterone up-regulates scavenger receptor $\mathrm{B} 1$ and stimulates cholesterol efflux from macrophages. Biochem Biophys Res Commun, 296:1051-7.

Larsen BA, Nordestgaard BG, Stender S, et al. 1993. Effect of T on atherogenesis in cholesterol-fed rabbits with similar plasma cholesterol levels. Atherosclerosis, 99:79-86.

Lee HJ, Chang C. 2002. Recent advances in androgen receptor action. Cellular and Molecular Life Sciences, 60:1613-22.

Ling S, Dai A, Dilley RJ, et al. 2004. Endogenous estrogen deficiency reduces proliferation and enhances apoptosis-related death in vascular smooth muscle cells: insights from the aromatase knock-out mouse. Circulation, 539-43.

Liu PY, Death AK, Handelsman DJ. 2003. Androgens and Cardiovascular disease. Endocrine Reviews, 24:313-40.

Malkin CJ, Pugh PJ, Jones TH, Channer KS. 2003. Testosterone for secondary prevention in men with ischaemic heart disease. Quart J Med, 96:521-9.

Malkin CJ, Jones RD, Jones TH, Channer KS. 2006. Effect of testosterone on ex vivo vascular reactivity in man. Clin Sci, 111:265-74.

Malkin CJ, Pugh PJ, West JN, et al. 2006. Testosterone therapy in men with moderate severity heart failure: a double-blind randomized placebo controlled trial. Eur Heart J, 27:57-64.

Marin P, Holmang S, Jonsson L, et al. 1992. The effects of testosterone treatment on body composition and metabolism in middle-aged obese men. Int J Obes Relat Metab Disord, 16:991-7.

Maron BJ, Shirani J, Poliac LC, et al. 1996. Sudden death in young competitive athletes Clinical, demographic and pathological profiles. JAMA, 276:199-204

Meriggiola MC, Marcovina S, Paulsen CA, et al. 1995. Testosterone enanthate at a dose of $200 \mathrm{mg} /$ week decreases HDL-cholesterol levels in healthy men. Int $J$ Androl, 18:237-42.

Mukherjee TK, Dinh H, Chaudhuri G, et al. 2002. Testosterone attenuates expression of vascular cell adhesion molecule-1 by conversion to estradiol by aromatase in endothelial cells: implications in atherosclerosis. PNAS, 99:4055-60.
Muller M, van den Beld AW, Bots ML, et al. 2004. Endogenous sex hormones and progression of carotid atherosclerosis in elderly men. Circulation, 109:2074-9.

Nathan L, Shi W, Dinh H, et al. 2001. Testosterone inhibits early atherogenesis by conversion to estradiol: critical role of aromatase. Proc Natl Acad Sci USA, 98:3589-93.

Ng M, Quinn CM, McCrohon JA, et al. 2003. Androgens up-regulate atherosclerosis-related genes in macrophages from males but not females: molecular insights into gender differences in atherosclerosis. $J$ Am Coll Cardiol, 42:1306-13.

Obasanjo IO, Clarkson TB, Weaver DS. 1996. Effects of the anabolic steroid nandrolone decanoate on plasma lipids and coronary arteries of female cynomolgus macaques. Metabolism, 45:463-8.

Page ST, Amory JK, Bowman FD, et al. 2005. Exogenous testosterone (T) alone or with finasteride increases physical performance, grip strength, and lean body mass in older men with low serum T. J Clin Endocrinol Metab, 90:1502-10.

Paradisi G, Steinberg HO, Hempfling A, et al. 2001. Polycystic ovary syndrome is associated with endothelial dysfunction. Circulation, 103:1410-15.

Polderman KH, Gooren LJ, Asscheman H, et al. 1994. Induction of insulin resistance by androgens and estrogens. J Clin Endocrinol Metab, 79:265-71.

Pugh PJ, Jones TH, Channer KS. 2003. Acute haemodynamic effects of testosterone in men with chronic heart failure. Eur Heart J, 24:909-15.

Quigley CA, DeBellis A, Marschke KB, et al. 1995. Androgen receptor defects: historical, clinical and molecular perspectives. Endocrinology Reviews, 16:271-321.

Reckelhoff JF. 2005. Sex steroids, cardiovascular disease and hypertension. Hypertension, 45:170-4.

Rosano GM, Leonardo F, Pagnotta P, et al. 1990. Acute anti-ischemic effect of testosterone in men with coronary artery disease. Circulation, 99:1666-70.

Ross R. 1999. Atherosclerosis- an inflammatory disease. $N$ Engl J Med, 340:115-26.

Rossouw JE, Prentice RL, Manson JE, Wu L, et al. 2007. Postmenopausal hormone therapy and risk of cardiovascular disease by age and years since menopause. JAMA, 297:1465-77.

Seyrek M, Yildiz O, Ulusoy HB, Yildrim V. 2007. Testosterone relaxes isolated human radial artery by potassium channel opening action. $J$ Pharmocological Sciences, 103:309-16.

Snyder PJ, Peachey H, Berlin JA, et al. 2001. Effect of transdermal testosterone treatment on serum lipid and apolipoprotein levels in men more than 65 years of age. Am J Med, 111:255-60.

Stellato RK, Feldman HA, Hamby O, et al. 2000. Testosterone, sex hormone binding globulin and the development of type 2 diabetes in middle aged men. Diabetes Care, 23:490-4.

Svartberg J, von Muhlen D, Schirmer H, et al. 2004. Association of endogenous testosterone with blood pressure and left ventricular mass in men: the Tromso Study. Eur J Endocrinol, 150:65-71.

Tchernof A, Labrie F, Belanger A, et al. 1997. Relationships between endogenous steroid hormone, sex hormone-binding globulin and lipoprotein levels in men: contribution of visceral obesity, insulin levels and other metabolic variables. Atherosclerosis, 133:235-44.

Thomas H, Dadgar N, Aphale A, et al. 2004. Androgen receptor acetylation site mutations cause trafficking defects, misfolding, and aggregation similar to an expanded glutamine tracts. Journal of Biological Chemistry, 279:8389-95.

Toda T, Toda Y, Cho BH, et al. 1984. Ultrastructural changes in the comb and aorta of chicks fed excess testosterone. Arteriosclerosis, $51: 47-53$.

Tracy RE. 1966. Sex differences in coronary disease: two opposing views. J Chronic Dis, 19:1245-51.

Trapman J, Ris-Stalpers C, van der Korput JA, et al. 1990. The androgen receptor: functional structure and expression in transplanted human prostate tumors and prostate tumor cell lines. Journal of Steroid Biochemistry and Molecular Biology, 37:837-42. 
van Kesteren P, Asschemen H, Megens JAJ, et al. 1997. Mortality and morbidity in transsexual subjects treated with cross-sex hormones. Clin Endocrinol, 47:337-42.

Vermeulen A, Kaufman JM. 2002. Diagnosis of hypogonadism in the aging male. Aging Male, 5:270-6.

von Dehn G, von Dehn O, Volker W, et al. 2001. Atherosclerosis in apolipoprotein E-deficient mice is decreased by the suppression of endogenous sex hormones. Horm Metab Res, 33:110-4.

Webb CM, Adamson DL, de Zeigler D, et al. 1999. Effect of acute testosterone on myocardial ischemia in men with coronary artery disease. Am J Cardiol, 83:437-9.

Whitsel EA, Boyko EJ, Matsumoto AM, et al. 2001. Intramuscular testosterone esters and plasma lipids in hypogonadal men: a meta-analysis. Am J Med, 111:261-9.

Wierman ME. 2007. Sex steroid effects at target tissues: mechanisms of action. Advances in Physiology Education, 31:26-33.

Woodard TL, Burghen GA, Kitabchi AE, Wilimas JA. 1981. Glucose intolerance and insulin resistance in aplastic anemia treated with oxymetholone. J Clin Endocrinol Metab, 53:905-8.
Wu FC, Farley TM, Peregoudov A, Waites GM. 1996. Effects of testosterone enanthate in normal men: experience from a multicenter contraceptive efficacy study. World Health Organization Task Force on Methods for the Regulation of Male Fertility. Fertil Steril, 65:626-36.

Wu FC, von Eckardstein A. 2003. Androgens and coronary artery disease Endocrine Reviews, 24:183-217.

Yeap BB, Krueger RG, Leedman PJ. 1999. Differential posttranscriptional regulation of androgen receptor gene expression by androgen in prostate and breast cancer cells. Endocrinology, 140:3282-91.

Zhou ZX, Kemppainen JA, Wilson EM. 1995. Identification of three proline-directed phosphorylation sites in the human androgen receptor. Molecular Endocrinology, 9:605-15.

Zmuda JM, Cauley JA, Kriska A, et al. 1997. Longitudinal relation between endogenous testosterone and cardiovascular disease risk factors in middle-aged men. A 13-year follow-up of former Multiple Risk Factor Intervention Trial participants. Am J Epidemiol, 146:609-17. 
